\title{
Uncertainty in counting ice nucleating particles with continuous flow diffusion chambers
}

\author{
Sarvesh Garimella ${ }^{1}$, Daniel A. Rothenberg ${ }^{1}$, Martin J. Wolf ${ }^{1}$, Robert O. David ${ }^{2}$, Zamin A. Kanji ${ }^{2}$, Chien Wang ${ }^{1}$, \\ Michael Rösch ${ }^{1}$, and Daniel J. Cziczo ${ }^{1,3}$ \\ ${ }^{1}$ Department of Earth, Atmospheric and Planetary Sciences, Massachusetts Institute of Technology, Cambridge, MA, USA \\ ${ }^{2}$ Institute for Atmospheric and Climate Science, ETH Zurich, Zurich, Switzerland \\ ${ }^{3}$ Department of Civil and Environmental Engineering, Massachusetts Institute of Technology, Cambridge, MA, USA
}

Correspondence to: Daniel J. Cziczo (djcziczo@mit.edu)

Received: 28 December 2016 - Discussion started: 31 January 2017

Revised: 19 May 2017 - Accepted: 5 June 2017 - Published: 14 September 2017

\begin{abstract}
This study investigates the measurement of ice nucleating particle (INP) concentrations and sizing of crystals using continuous flow diffusion chambers (CFDCs). CFDCs have been deployed for decades to measure the formation of INPs under controlled humidity and temperature conditions in laboratory studies and by ambient aerosol populations. These measurements have, in turn, been used to construct parameterizations for use in models by relating the formation of ice crystals to state variables such as temperature and humidity as well as aerosol particle properties such as composition and number. We show here that assumptions of ideal instrument behavior are not supported by measurements made with a commercially available CFDC, the SPectrometer for Ice Nucleation (SPIN), and the instrument on which it is based, the Zurich Ice Nucleation Chamber (ZINC). Non-ideal instrument behavior, which is likely inherent to varying degrees in all CFDCs, is caused by exposure of particles to different humidities and/or temperatures than predicated from instrument theory of operation. This can result in a systematic, and variable, underestimation of reported INP concentrations. We find here variable correction factors from 1.5 to 9.5 , consistent with previous literature values. We use a machine learning approach to show that non-ideality is most likely due to small-scale flow features where the aerosols are combined with sheath flows. Machine learning is also used to minimize the uncertainty in measured INP concentrations. We suggest that detailed measurement, on an instrument-byinstrument basis, be performed to characterize this uncertainty.
\end{abstract}

\section{Introduction}

Aerosol particles affect the climate system via their ability to interact with radiation and act as the sites upon which water condenses to form liquid and ice clouds (Pruppacher and Klett, 1997; Seinfeld and Pandis, 2006; Boucher et al., 2013). Those that facilitate ice crystal formation above the temperature or below the humidity of homogeneous freezing are called ice nucleating particles (INPs) and affect the formation and persistence of mixed-phase and cirrus clouds (Forster et al., 2007). The interactions between INPs and cold clouds are a measurement challenge because such clouds occur either high in the atmosphere or near the poles and are difficult to access (Rossow and Schiffer, 1999). Continuous flow diffusion chambers (CFDCs) have provided a means to understand ice cloud formation by measuring INP concentrations in the field. By exposing an ambient aerosol population to controlled humidity and temperature conditions, the ability of natural aerosols to act as INPs can be quantified (DeMott et al., 2003a, b; Chou et al., 2011; Boose et al., 2016).

Measurements of INP concentration using CFDCs have been used to construct model parameterizations that relate the formation of ice crystals to temperature and aerosol particle number and size (DeMott et al., 2010, 2015; Tobo et al., 2013). Using such parameterizations, global aerosol transport models attempt to link aerosol emissions to their potential to impact ice cloud formation and thus climate (VergaraTemprado et al., 2017). The use of CFDC data for parameterization of ice formation in such models highlights the need for assessing the accuracy and bias of such measurements. 


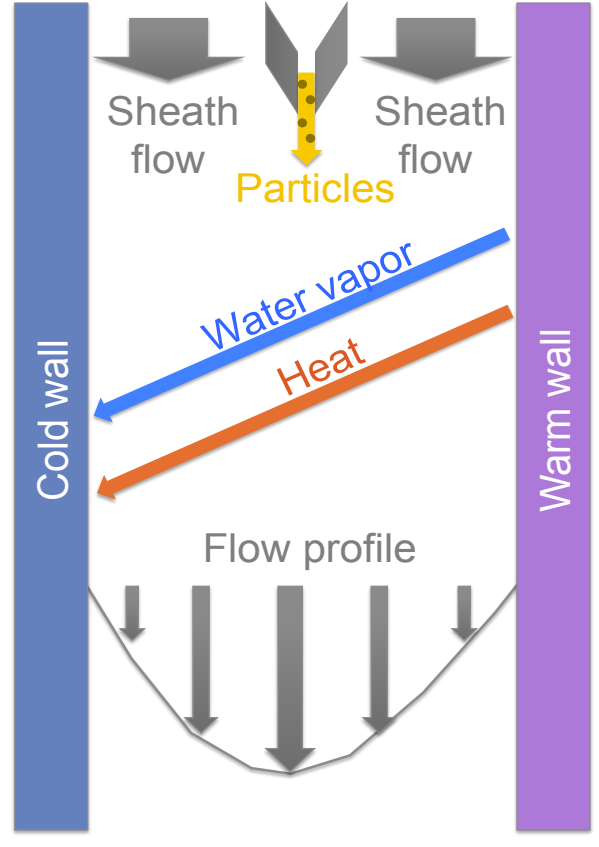

Figure 1. Schematic representation of an idealized CFDC. A particle-laden flow is passed between two ice-coated walls that are held at different temperatures below $0^{\circ} \mathrm{C}$. This results in water vapor and heat diffusing from the warm to the cold wall. Supersaturation, with a maximum near the centerline, results from the nonlinear relationship of water vapor saturation with respect to temperature. Sheath flows along each wall are meant to isolate particles to a central lamina at or near the supersaturation maximum, which also theoretically restricts the temperature and supersaturation to which they are exposed.

CFDC instruments are able to determine INP concentrations by drawing in aerosol particles and controlling the temperature and relative humidity to which they are exposed (Rogers, 1988; Stetzer et al., 2008; Garimella et al., 2016). Although there are instrument-to-instrument differences in geometry and flows, typically particles are drawn through an inlet and contained between two sheath flows (Fig. 1). These three flows pass between two ice-coated walls that are held at different sub- $0{ }^{\circ} \mathrm{C}$ temperatures. Water vapor and heat diffuse from the warm wall to the cold wall, such that approximately linear gradients of both quantities exist across the width of the chamber. Because the saturation vapor pressure exhibits a nonlinear temperature dependence, the air within the chamber is supersaturated with respect to ice. The variation in heat and vapor diffusion results in a maximum in supersaturation near the center of the chamber (Rogers, 1988). Particles constrained to a narrow central lamina by the sheath flows should, in theory, be exposed to only the maximum saturation with a small uncertainty in temperature and humidity. The fractional width of the lamina is typically taken to be the ratio of the incoming aerosol flow rate to the total (sample + sheaths) flow rate through the chamber (Rogers, 1988).
A sufficiently large temperature gradient between the walls can cause lamina conditions to not only exceed ice but also liquid water saturation (Rogers, 1988; Stetzer et al., 2008; Garimella et al., 2016). Droplet formation is important since many CFDCs measure only the size of objects exiting the chamber with an optical particle counter (OPC; Rogers, 1988; DeMott et al., 2015). The presence of droplets can therefore be misinterpreted as a higher abundance of ice crystals. The impact of droplet formation is minimized by the utilization of an "evaporation region" in most modern CFDCs. These regions are isothermal and ice-coated sections at the bottom of the chamber where small droplets are evaporated by subsaturated conditions with respect to liquid water. Nonetheless, a CFDC run with a sufficiently large temperature gradient between the walls can create droplets large enough to survive evaporation sections. This condition is known as "droplet breakthrough" and is specific to each CFDC's geometry and flow characteristics (Rogers, 1988; Stetzer et al., 2008; Garimella et al., 2016).

Instruments rarely follow theoretical predictions. In the case of CFDCs, this is often due to non-ideal flow and deviations from isothermal conditions. DeMott et al. (2015) discussed the effect of aerosol "spreading" outside the lamina as well as other possible factors that, in combination, could contribute to a low bias in the number of INP measured. Here, we extend the work of DeMott et al. (2015) with a quantitative analysis of the source and effect of spreading and discussion of the impact on CFDC data. For this work we use the Zurich Ice Nucleation Chamber (ZINC; Stetzer et al., 2008) and the commercial version, the SPectrometer for Ice Nucleation (SPIN; Garimella et al., 2016). We specifically considered effects in the regime supersaturated with respect to liquid water (immersion freezing) but believe these results are also applicable in the sub-saturated regime (depositional nucleation). The automation of these instruments, in particular the large amount of "housekeeping" data autonomously recorded to characterize SPIN instrument behavior, makes these chambers suitable for exploring this effect. We apply a machine learning algorithm for analysis in order to process the large amount of data and generate statistical inferences to constrain the spreading effect. We suggest the spreading effect can be best visualized as a deviation from laminar flow and non-isokinetic injection as the particles are drawn into the chamber. We conclude that the non-ideal conditions are likely universal but also dependent on the geometry and flow characteristics of each CFDC chamber.

\section{Methodology}

\subsection{Particle timing tests}

The ZINC and SPIN CFDCs have been described in detail previously (Stetzer et al., 2008; Garimella et al., 2016). To measure the degree of particle spreading outside the lamina a precise particle pulse was introduced into the chambers. In 

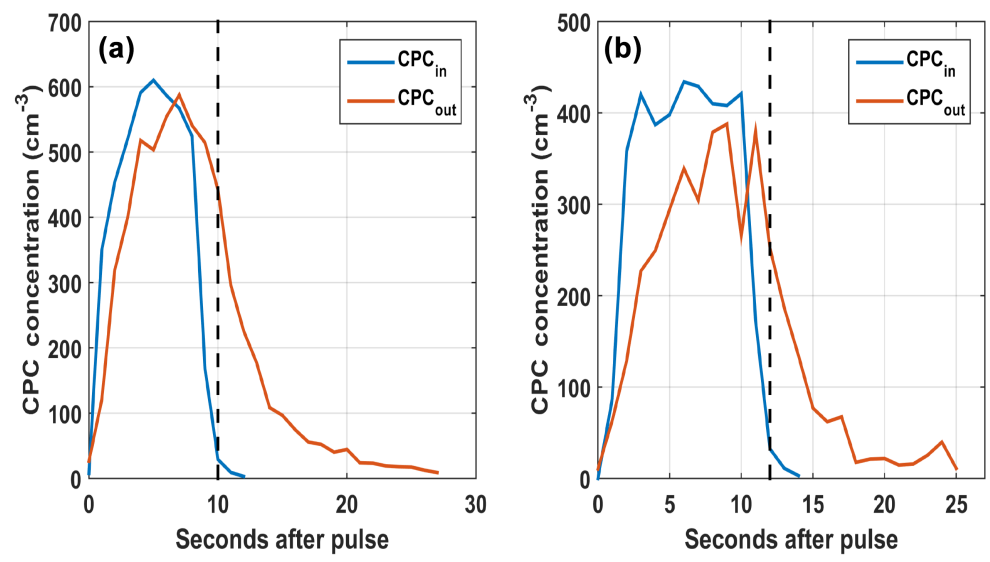

Figure 2. Particle concentration as a function of time for particle pulse experiments using ZINC. The blue traces are the counts measured at the entrance of the chamber $\left(\mathrm{CPC}_{\mathrm{in}}\right)$ while the red traces are the concentrations at the output $\left(\mathrm{CPC}_{\text {out }}\right)$. Both experiments were conducted at $-40{ }^{\circ} \mathrm{C}$ with (a) at $102 \% \mathrm{RH}$ and (b) at $110 \% \mathrm{RH}$, both with respect to liquid water. Particles in the red trace occurring after the vertical dashed line are outside the initial pulse duration and are inferred to have moved out of the lamina. The ratio of particles within the pulse time at the outlet versus the total particles were 78 (a) and $76 \%$ (b), respectively.

the case of SPIN this was a $1 \mathrm{~s}$ pulse with automated valves, while for ZINC a $\sim 10$ s pulse was used with manual valves. In both cases, a valve at the chamber inlet was used to control the pulse. Under ideal conditions, regardless of duration, this should correspond to an equivalent particle pulse at the chamber outlet. Non-idealities have been shown to lead to particle spreading across the width of the chamber as they traverse its length by DeMott et al. (2015). For this work, the arrival of particles was measured at the chamber outlet with a condensation particle counter (CPC, Brechtel, Inc. model (BMI) 1720 for SPIN, and a TSI CPC 3772/3787 for ZINC). A wider particle pulse (in time) measured at the outlet indicates more spreading of the particles across the width of the chamber, since the fastest particles travel closer to the center of the chamber under a laminar flow assumption. This is shown in Fig. 2 for ZINC experiments at a total flow rate of $10 \mathrm{~L} \mathrm{~min}^{-1}$ and chamber conditions of $-40^{\circ} \mathrm{C}$ and $102 \%$ relative humidity (RH, panel a) and $110 \% \mathrm{RH}$ with respect to water (panel b). This temperature was used to determine the variation of particle loss with respect to temperature from the lamina and because it is in the homogeneous freezing regime where all test particles should be able to nucleate ice. At this lamina temperature the difference between the wall temperatures is larger for a given supersaturation than at a higher temperature and this maximized any resulting turbulence effect on particle migration from the lamina. $10 \mathrm{~s}$ pulses were produced with $200 \mathrm{~nm}$ ammonium nitrate (Sigma Aldrich) particles which were wet-generated using an atomizer and size selected with a differential mobility analyzer (TSI DMA 3082). CPC measurement at the input $\left(\mathrm{CPC}_{\mathrm{in}}\right)$ verifies production of a $\sim 10$ s pulse while the output particles $\left(\mathrm{CPC}_{\text {out }}\right)$ continue for 20-30 s.

The SPIN data exhibit the same behavior. SPIN particle distributions were measured for twenty-five $1 \mathrm{~s}$ aerosol pulses at constant isothermal conditions of $20^{\circ} \mathrm{C}$ and $\sim 10 \mathrm{~L} \mathrm{~min}^{-1}$ flow; $100 \mathrm{~nm}$ diameter ammonium sulfate particles wet-generated and dried with a BMI 9203 aerosol generator and mobility diameter selected with a BMI model 2100 differential mobility analyzer were used. Combining information from a measured particle pulse and a calculated velocity profile, the corresponding distribution of particles across the width of the chamber for that particular pulse can be inferred (Fig. 3). Buoyancy effects on mean chamber flow and mean particle position are accounted for in the calculation of the velocity profiles (Rogers, 1988). The particle distributions are reconstructed by assigning the first detected particles to the maximum velocity position in the calculated flow profile and the assigning peak particle concentration to the calculated lamina position (about which spreading occurs). The particles in the tail of the pulse are assigned positions corresponding to their relative velocities, which are derived from their relative arrival times.

A further $\sim 250$ pulse measurements using polydisperse ambient aerosol particles were conducted using the SPIN setup at Storm Peak Laboratory (Steamboat Springs, Colorado, $3220 \mathrm{~m}$ a.s.1.; $40.455^{\circ} \mathrm{N},-106.744^{\circ} \mathrm{W}$ ) to capture the spreading effect variability in an environment where INP field measurement campaigns occur (DeMott et al., 2003a). These tests were across a range of chamber thermodynamic conditions (lamina humidities between ice and water saturation at temperatures -15 to $-40^{\circ} \mathrm{C}$ ). We note that diffusive and other forces may differ across particle sizes. Monodisperse particles were tested under laboratory and polydisperse particles under field conditions; future studies may consider a full range of particle sizes applicable to particular CFDCs. 


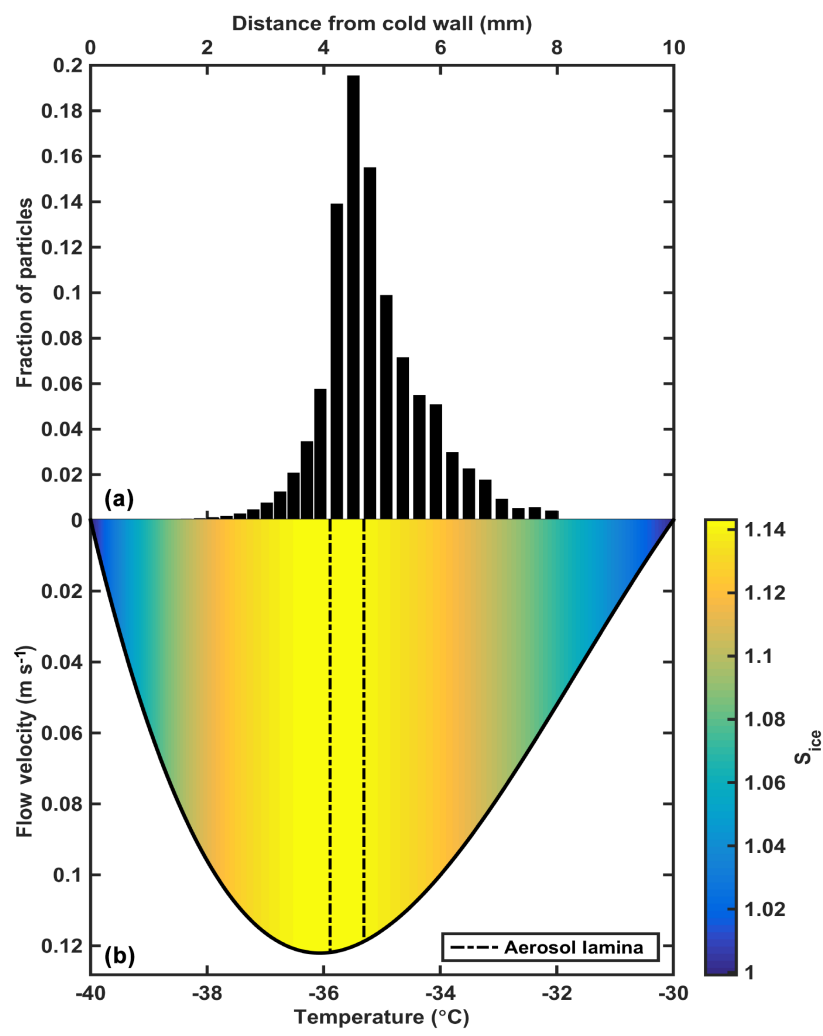

Figure 3. Measured particle distribution across the chamber in the SPIN CFDC (a; see text for details) corresponding to the velocity profile and $S_{\text {ice }}$ as a function of temperature across the chamber (b). The dash-dotted lines show the location of particles if they were constrained to the theoretical aerosol lamina. Note that while the peak particle concentration correctly occurs within the lamina, some particles have migrated into the sheath and are therefore exposed to higher and lower temperatures and supersaturation lower than the maximum.

\subsection{Machine learning prediction}

A random forest regression (RFR; Breiman, 2001) was used to predict the fraction of particles that remained in the aerosol lamina (hereafter " $f_{\text {lam }}$ "). In this application RFR is similar to a multiple linear regression except that it grows a forest of bootstrap-aggregated (or "bagged") decision trees to fit the data instead of using a linear model. Bootstrap aggregation avoids overfitting the data, provides uncertainty quantification for each prediction using the out-of-bag (oob) prediction error, ranks the variables by their importance by comparing oob prediction errors and does not assume linear relationships between variables (Breiman, 2001). First, the complete set of housekeeping variables recorded for SPIN is input into the RFR, for which they are termed "features". This housekeeping data set is normally recorded to verify instrument operation, and no a priori assumptions are made as to which variables are the most important predictor of $f_{\text {lam }}$. The RFR indicates the most important predictors by comparison to the
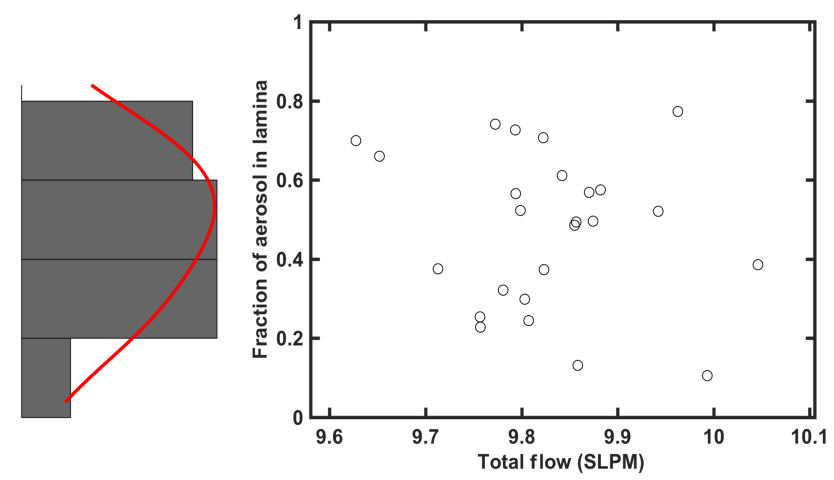

Figure 4. Measured $f_{\text {lam }}$ as a function of total flow in SPIN at $20^{\circ} \mathrm{C}$, varied around a nominal value of $9.8 \mathrm{slpm}$. In the ideal case, where all particles are constrained with the dash-dotted lines in Fig. 2, data points should form a horizontal line at 1.0. This figure illustrates that the ideal condition is not realized and that even within a few $\%$ of the nominal total flow of $9.8 \mathrm{~L} \mathrm{~min}^{-1}$, the fraction of particles in the lamina is not predictable. The histogram on the left is a distribution of $f_{\text {lam }}$ with the corresponding kernel density estimate shown in red.

experimental pulse results. As an example, ambient temperature might not be expected to be an important factor in the spreading effect but it was not removed from the data set; that decision was left to the RFR. Feature importance was observed to fall exponentially and those within the first two e-folding lengths of importance were maintained in a reduced RFR model. The reduced RFR subset included 65 variables including wall temperature, flows, and saturation conditions predominantly in the middle and top sections of the SPIN chamber (Garimella et al., 2016); this is the region of the chamber where aerosol is initially encased within the sheath flows. This suggests that turbulence or other small-scale flow features in this region are responsible for the spreading effect in the region where the particle flow is injected into the chamber. However, we can not preclude that other processes taking place in this region, such as thermophoresis, are not also partially responsible. The top 10 most important features are listed in Table 1.

\section{Results and discussion}

Figure 4 shows the results from the 25 particle timing tests at $20^{\circ} \mathrm{C}$ and $\sim 10 \mathrm{~L} \mathrm{~min}^{-1}$ flow conditions. Wall temperatures remained within $\pm 1^{\circ}$ of the set point for all experiments. The fraction of particles that remained in the aerosol lamina varied despite constant flow, aerosol properties and temperature. Figure 5 shows the results from 267 ambient particle pulse experiments in the aforementioned temperature and saturation range. In Fig. 5, $f_{\text {lam }}$ is plotted against the lamina temperature and ice saturation ratio $\left(S_{\text {ice }}\right)$ calculated for walls at ice saturation and with temperatures corresponding to the measurement average value (Garimella et al., 2016). 

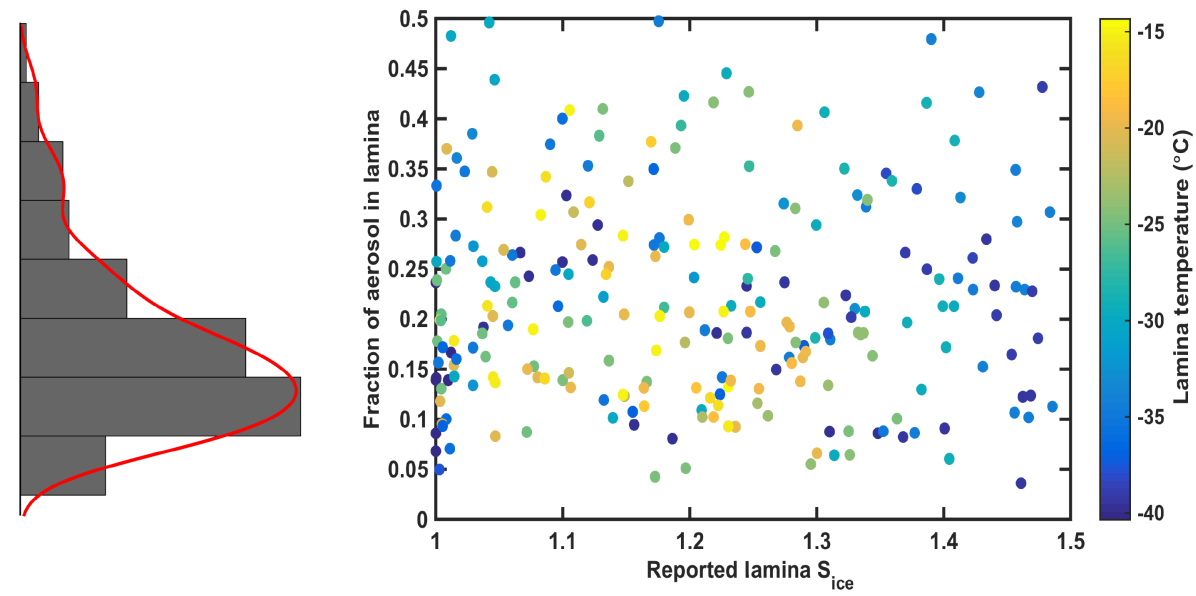

Figure 5. Measured $f_{\text {lam }}$ as a function of $S_{\text {ice }}$ in the aerosol lamina in SPIN. Temperature for each data point is noted by the color bar. The histogram on the left is the distribution of $f_{\text {lam }}$ from the measurements with the corresponding kernel density estimate shown in red.

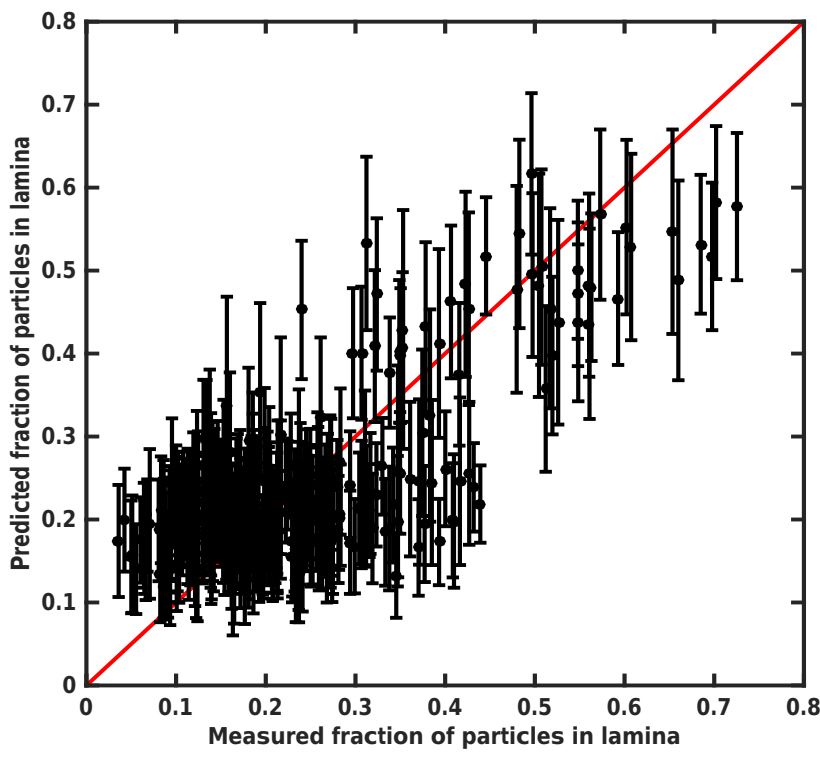

Figure 6. Random forest regression prediction versus measured $f_{\text {lam }}$ using the 65 SPIN variables determined by the algorithm to be most important (see text for details). Data points are the mean value predicted and error bars correspond to the standard deviation of the predictions by the random forest. A one-to-one line is shown in red.

Data are not highly correlated to either. The mean and standard deviation of $f_{\text {lam }}$ are $0.25 \pm 0.14$ and, depending on the specific conditions, the distribution exhibits values that vary between 0.03 and 0.7 (i.e., between 3 and $70 \%$ of particles were within the lamina).

The reduced RFR described in Sect. 2.2 can be used to predict $f_{\text {lam }}$ (mean values and standard deviations) based on the SPIN variables shown to be most important. Figure 6 shows the performance of this approach, which has an oob mean squared prediction error of 0.008 , whereas simply selecting
Table 1. List of the ten most important features from the RFR. TC corresponds to thermocouple and $\mathrm{H}$ to heater (supplemental heating is used to maintain wall isothermality in the SPIN chamber) where numbers correspond to locations described in Garimella et al. (2016). Lamina saturation is calculated at specific locations using temperature measurements and assuming walls exist at ice saturation per the method outlined in Garimella et al. (2016). The features are predominantly located in the top and middle sections of the chamber.

\begin{tabular}{ll}
\hline $\begin{array}{l}\text { Feature } \\
\text { rank }\end{array}$ & Feature name \\
\hline 1 & Lamina saturation at TC3 \\
2 & Average $\Delta$ T between warm and cold wall \\
3 & Lamina saturation at TC4 \\
4 & Warm wall H0 on/off time \\
5 & Lamina saturation at TC1 \\
6 & Lamina saturation at TC11 \\
7 & Average warm wall temperature spread \\
8 & Lamina saturation at TC5 \\
9 & Average warm wall temperature difference \\
& from set point \\
10 & Total volume flow \\
\end{tabular}

the mean value for $f_{\text {lam }}$ from the distribution in Fig. 5 results in a mean squared error for predicting $f_{\text {lam }}$ of $\sim 0.02$. Thus, the RFR approach reduces the uncertainty by $\sim 60 \%$.

DeMott et al. (2015) noted the non-ideality, including due to particles spreading beyond the lamina, in the Colorado State University CFDC chamber. They proposed the use of a "calibration factor" (cf) by which the measured INP number could be multiplied to provide a corrected value. Previous studies, including Tobo et al. (2013), used $\mathrm{cf}=1$; this corresponds to an assumption that all particles in a CFDC exist within the lamina. It should be noted particle properties, such as size, shape and hygroscopicity, may have an effect on the 
cf and that the value found by DeMott et al. (2015) may not be universal even for that CFDC. The value of $\mathrm{cf}=3$ does correspond to a constant $33 \%$ of particles existing within the lamina, regardless of flow or thermodynamic state, for those experiments. The distribution found here corresponds to a variable correction factor in the range of $\mathrm{cf}=1.4$ to 9.5 , depending on the experiment, with a mean of 4 . We note the $\mathrm{cf}=3$ value reported by DeMott et al. (2015) is for a different CFDC but falls within the range measured here. This suggests that cf could depend on various instrument control factors and would require RFR analysis for the various CFDC configurations to predict cf.

Further evidence to support the spreading effect is provided by the size of the ice crystals measured at the output of a CFDC. Theoretically, a monodisperse population of an aerosol composition that only nucleates ice homogeneously should exhibit freezing almost at the same time and location within a CFDC chamber. This is because particles should equilibrate with the internal chamber conditions within $\sim 1 \mathrm{~s}$ of entering the chamber and then freeze rapidly due to the resulting nucleation rate at these conditions (Koop et al., 2000). This should translate to a quasi-monodisperse ice crystal size distribution at the chamber output. The size of the ice crystals should be a function of the chamber RH and temperature and equivalent to the amount of vapor-deposited water under these conditions. Therefore, differences in ice crystal size should primarily be due to particles that leave the lamina and experience varying supersaturations and residence times in the chamber. The result of the extended time it takes for particles to exit the chamber due to spreading would be (1) larger crystals due to extended time in a supersaturated region and (2) a broadening of the ice crystal size distribution due to residence time and supersaturation variability the particles are exposed to. Experiments run with the ZINC chamber confirm a non-monodisperse ice crystal size distribution (Fig. 7).

In order to consider the effect of spreading beyond the lamina, aerosol particles were assumed to nucleate ice upon entering the chamber since the $-40^{\circ} \mathrm{C}$ lamina temperature was below that required for homogeneous ice nucleation. We note there is a short delay not directly accounted for in this calculation for thermal equilibration $\left(\sim 0.1-0.8 \mathrm{~s}\right.$ at $-40^{\circ} \mathrm{C}$ assuming heat transfer coefficients for the $\mathrm{NH}_{4} \mathrm{NO}_{3}$ particles) and $\sim 1.0 \mathrm{~s}$ for the particles to travel to the ice-coated region of the chamber (Stetzer et al., 2008). The combination of velocity profile and residence time from the pulse experiments (Fig. 2) were then used to determine the location of the particles in the lamina and therefore the time they were exposed to variable supersaturation and the subsequent size to which they would grow.

The baseline crystal size was when all particles remained within the predicted lamina (i.e., within the dashed lines in Fig. 2). Ice crystal size was calculated per the formulation of Rogers and Yau (1989). Crystals were assumed to be spherical due to the ice forming homogeneously from submicrometer diameter particles (Järvinen et al., 2016). The
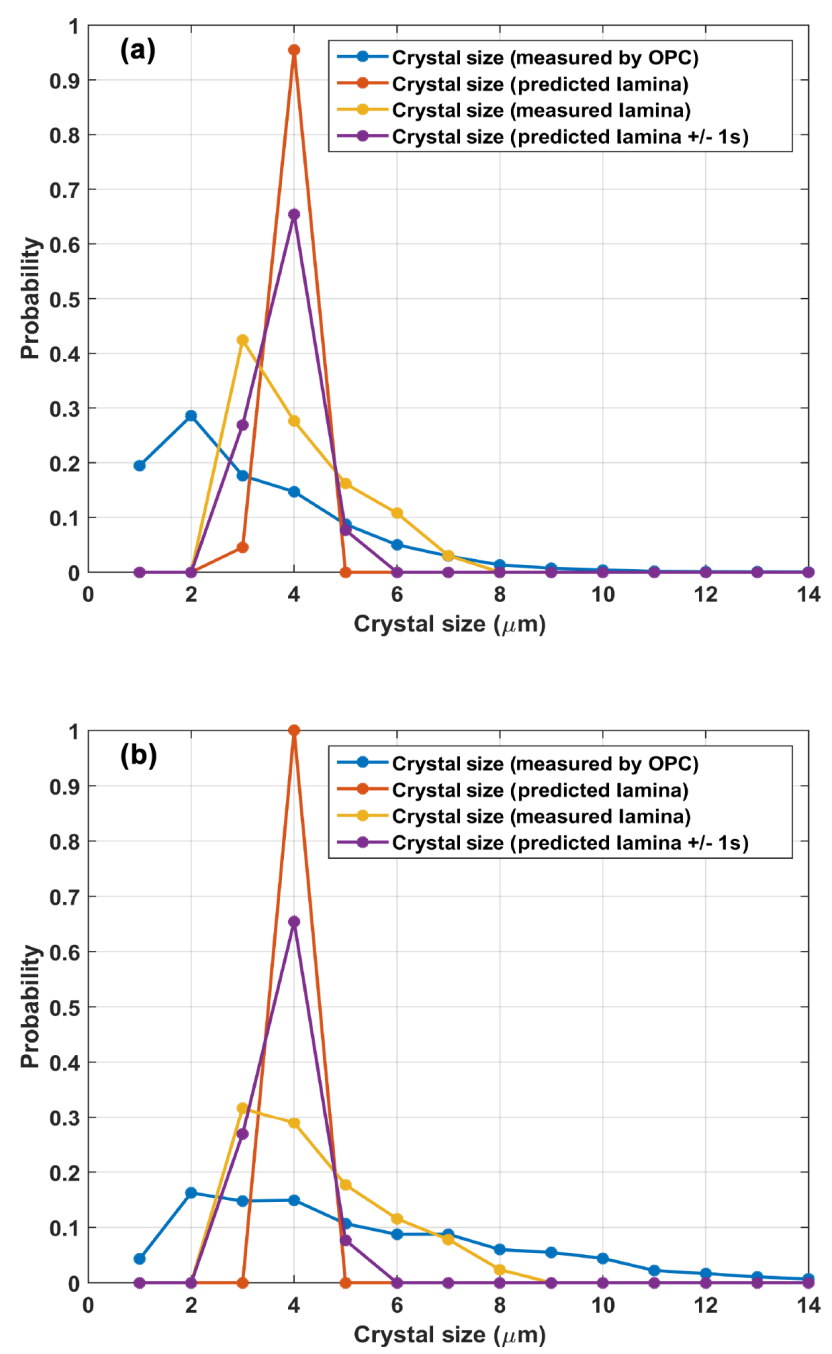

Figure 7. Probability histogram of ice crystal diameter. Both experiments were conducted at $-40{ }^{\circ} \mathrm{C}$ with (a) at $102 \% \mathrm{RH}$ and (b) at $110 \% \mathrm{RH}$, both with respect to liquid water. In the predicted case all particles are assumed to remain within the lamina, nucleate ice and grow to the same final size (red). The ice crystal size distribution becomes broader if particles are allowed to exist in the chamber for $1 \mathrm{~s}$ shorter or longer than predicted (purple). Ice crystal size predictions using the spreading time indicated in Fig. 2 results in the yellow histogram. Note that the ice crystal size predictions using the measured spreading time (yellow) most closely matches the measured ice crystal size distribution (blue) from the ZINC OPC.

initial ice crystal size was assumed to be that of ammonium nitrate at the initial dry diameter, which may be a slight underestimation due to hygroscopic growth before freezing occurred. However, calculations with a doubling of the initial particle size had minimal impact on the final ice crystal size so this assumption was maintained for all calculations. An accommodation coefficient of 0.2 (Skrotzki et al., 2013) and the calculated residence time in the lamina $(\sim 10 \mathrm{~s})$ were used to predict the ice crystal sizes. The calculations resulted 


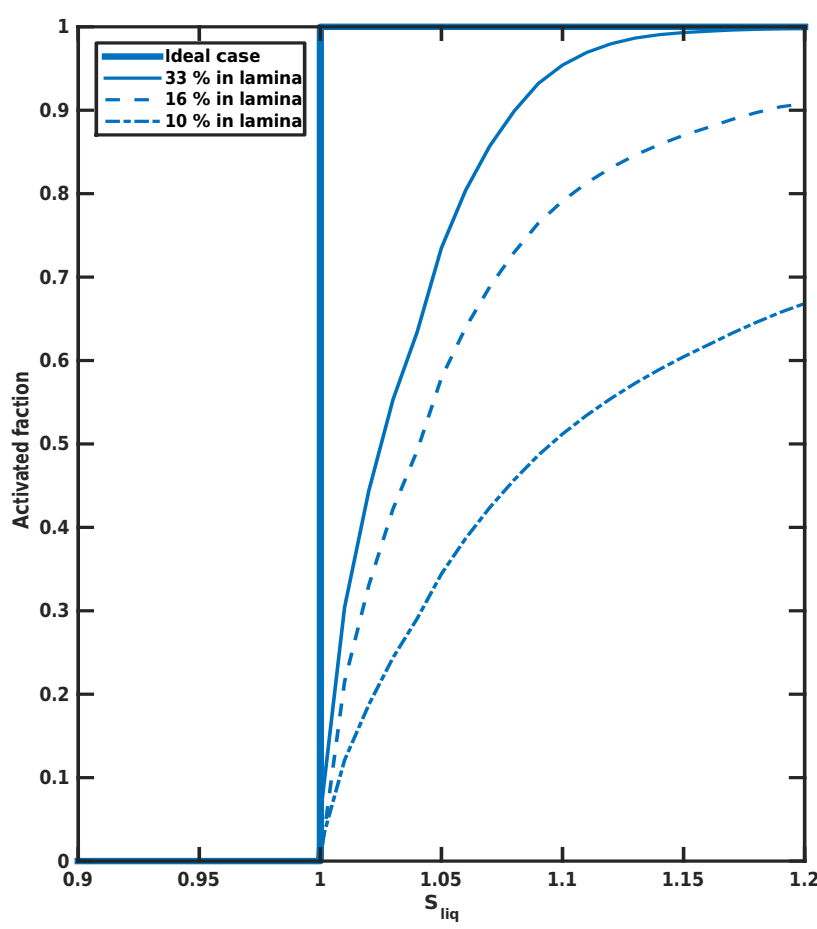

Figure 8. Fraction of particles that activate as a function of saturation with respect to liquid water. All particles are assumed to be perfect immersion INPs which activate as ice crystals when exposed to water saturation $\left(S_{\text {liq }}=1\right)$. In the ideal case, where all particles are constrained within the lamina ( $f_{\text {lam }} 100 \%$; all particles exist within the dash-dotted lines in Fig. 2), all nucleation occurs at a CFDC saturation of $S_{\text {liq }}=1$ (bold solid line). The other three curves correspond to increasingly less ideal behavior (i.e., increasingly fewer particles in the lamina and existing farther from the centerline), corresponding to $f_{\text {lam }}$ falling from 33 to $10 \%$. In these cases an increasingly higher maximum CFDC saturation is required so that the particles farthest from the centerline experience $S_{\text {liq }}=1$.

in monodisperse ice crystals at $\sim 4 \mu \mathrm{m}$ diameter (Fig. 7, red histogram).

If minor spreading in time with respect to that predicted when particles remain in the lamina is allowed at the level of $\pm 1 \mathrm{~s}$, the ice crystal size distribution broadened (3-4 $\mu \mathrm{m}$ diameter; Fig. 7, purple histogram). The extended time that ice crystals were observed to remain in ZINC experiments (Fig. 2) caused a further broadening in ice crystal size distribution (3-7 $\mu \mathrm{m}$ diameter; Fig. 7, yellow histogram). The measured ice crystal size distribution (Fig. 7, blue histogram) shows particles predominantly from 2 to $7 \mu \mathrm{m}$ and is most consistent with the calculations made for ice crystal growth that include the spreading effect. It is important to note that the previous calculations are from a simple ice growth model and are used to illustrate that observed ice crystal size distributions are also consistent with particles spreading beyond the lamina. In addition to spreading, there are other reasons that ice crystals smaller than the theoretical size might exist. These include uncertainty in shape and in refractive index

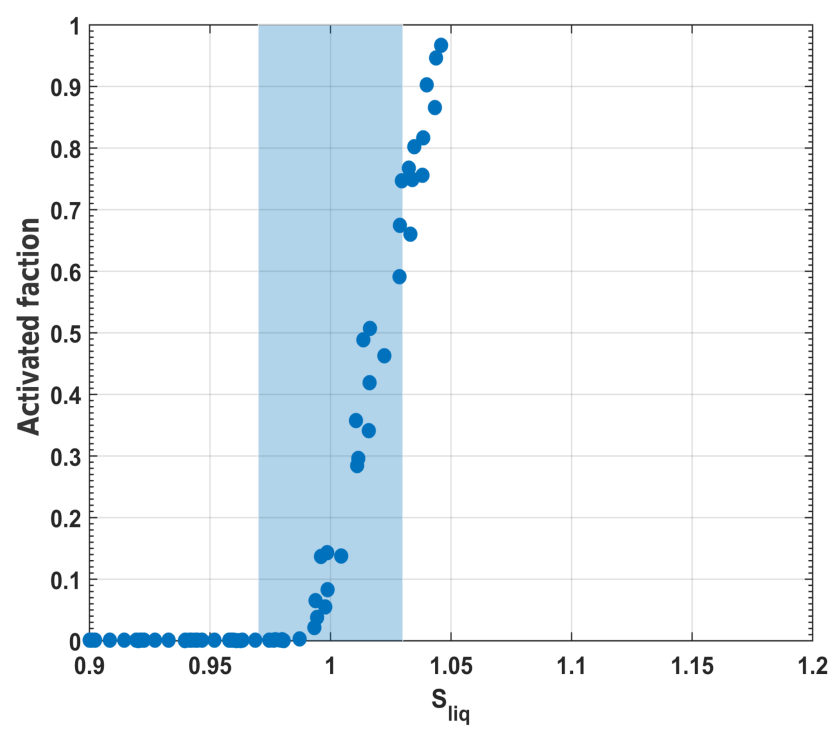

Figure 9. Fraction of $400 \mathrm{~nm}$ (dry diameter) $\mathrm{NH}_{4} \mathrm{NO}_{3}$ particles freezing homogenously as a function of $S_{\text {liq }}$ in ZINC at $-40^{\circ} \mathrm{C}$. For these conditions particles should freeze at $S_{\text {liq }} \sim 0.99$ (Koop et al., 2000). Shaded region indicates the range and uncertainty of $S_{\text {liq }}$ that the aerosol in the lamina are exposed to.

as well as crystals that are undersized by passing through the edge of the ZINC OPC (Stetzer et al., 2008). Furthermore, literature values of accommodation coefficient range between 0.2 and 1 (e.g., Skrotzki et al., 2013). Here, 0.2 was used for these calculations. A value of 0.1 would result in $\sim 10 \%$ smaller ice crystals, which is still not sufficient to fully account for the ice crystals of $<2 \mu \mathrm{m}$ diameter observed in the OPC.

The effect of particle spreading outside the lamina on CFDC reports of INP concentration measurements can be visualized using the data collected here. Fig. 8 shows idealized activation curves (i.e., nucleation of ice or droplets) at various $f_{\text {lam }}$ values. Note that $f_{\text {lam }}$ and cf can be thought of interchangeably where $33 \%$ and 3 are respectively (inversely) equivalent. In Fig. 8, the aerosol population is assumed to be comprised of idealized "perfect" immersion-mode INPs that form ice crystals immediately upon exposure at water saturation $\left(S_{\mathrm{liq}}=1\right)$; this could be viewed as a laboratory test of effective immersion INPs. In the case where the CFDC is assumed to operate ideally, all particles are constrained within the lamina $\left(f_{\text {lam }}=100 \%\right)$ and all nucleation occurs at $S_{\text {liq }}=1$ (solid line). The other three curves in Fig. 8 correspond to increasingly less ideal behavior (i.e., increasingly fewer particles in the lamina), corresponding to $f_{\text {lam }}$ falling from 33 to $10 \%$. The deviation from the ideal case can be viewed as a higher than saturation condition required at the centerline so the particle farthest outside the lamina experiences this value. These curves can also be interpreted as cases where $\mathrm{cf}$ is fixed but increases from 3 , the value suggested by DeMott et al. (2015), to 10, the worst case found in this work. 

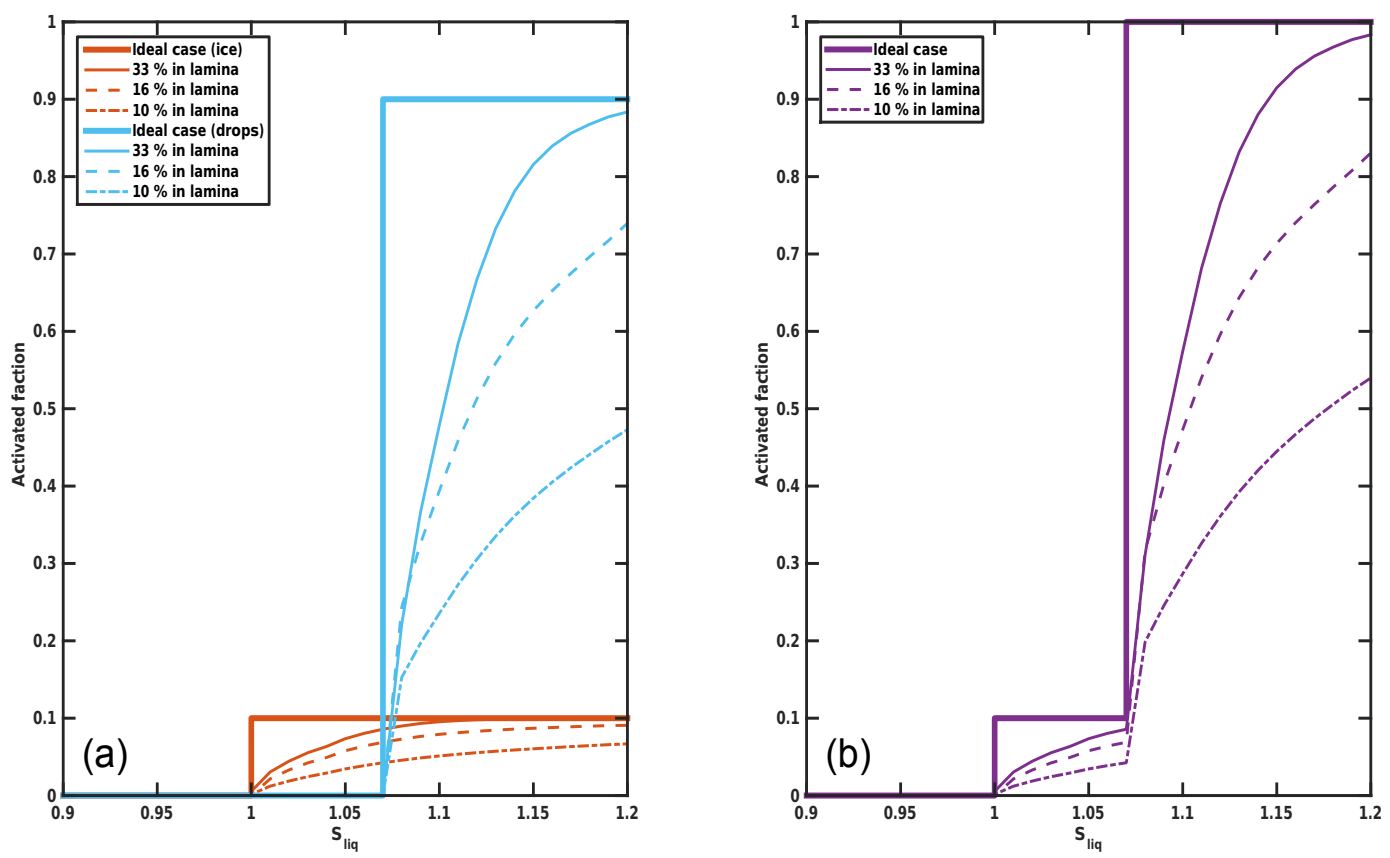

Figure 10. Fraction of particles that activate as a function of saturation with respect to liquid water. Unlike Fig. 8, where all particles are assumed to be perfect immersion INPs which activate as ice crystals when exposed to water saturation $\left(S_{\text {liq }}=1\right)$, only $10 \%$ of particles are assumed to be perfect immersion INPs. In the ideal case where all particles are constrained within the lamina $\left(f_{\text {lam }} 100 \%\right.$; all particles exist within the dash-dotted lines in Fig. 2), $10 \%$ of particles nucleate ice at a CFDC saturation of $S_{\text {liq }}=1$ (a, bold red line). The remaining $90 \%$ of particles are assumed to be perfect $\mathrm{CCN}$ that activate at $S_{\text {liq }}=1$. Droplets only survive the evaporation region of the chamber at $S_{\text {liq }}>1.07$ (corresponding to a "droplet breakthrough" point; bold blue line - see text and Garimella et al. (2016) for details). The other three curves correspond to the increasingly less ideal behavior presented in Fig. 8, with $f_{\text {lam }}$ falling from 33 to $10 \%$. In these cases, an increasingly higher maximum CFDC saturation is required so that the particles farthest from the centerline experience $S_{\text {liq }}=1$ and 1.07 . The resulting activation curves if droplets and ice crystals are indistinguishable, as is the case for an OPC (i.e., a composite of the red and blue traces in a) is shown in (b).

Homogeneous freezing experiments conducted in ZINC with $400 \mathrm{~nm}$ dry diameter $\mathrm{NH}_{4} \mathrm{NO}_{3}$ particles (see Fig. 9) demonstrate that $S_{\text {liq }}>0.99$ (as predicted by Koop et al., 2000) is required for all particles to freeze at $-40^{\circ} \mathrm{C}$, even after accounting for uncertainties in $S_{\text {liq }}$ (Fig. 9, shown in blue shading) of the lamina. Furthermore, within this uncertainty, $\sim 70 \%$ of the particles freeze in ZINC, consistent with the pulse tests, as shown in Fig. 2, if counting uncertainties of $\sim 14 \%$ arising from the CPC and OPC are considered. Indeed, to observe $100 \%$ of particles freezing, $S_{\text {liq }}=1.05$ must be reached in ZINC, suggesting that $\sim 30 \%$ of the particles escape the lamina even in the best observed case presented in this work. In the example of Fig. 9, quoting an active fraction at a specific $S_{\text {liq }}<1.05$ would result in underestimating this value as we know in an ideal case (no lamina spreading) the active fraction should be unity at $S_{\text {liq }}=1$.

Figure 10 expands on Fig. 8 by considering another idealized case, but one more applicable to measurement of an ambient aerosol population. In this case only $10 \%$ of the particles are perfect immersion-mode INPs, whereas the rest are cloud condensation nuclei $(\mathrm{CCN})$ that activate at exactly $S_{\text {liq }}=1$. The evaporation section on the bottom of the heuris- tic chamber causes droplets to evaporate until breakthrough at $S_{\text {liq }}>1.07$ (Garimella et al., 2016). In the ideal case all particles are constrained within the lamina and $10 \%$ of particles nucleate ice at a CFDC saturation of $S_{\text {liq }}=1$ (panel a, solid black line). The remaining $90 \%$ of particles break through as droplets at $S_{\mathrm{liq}}>1.07$ (panel a, solid blue line). The other three curves correspond to the increasingly less ideal behavior presented in Fig. 8, corresponding to $f_{\text {lam }}$ falling from 33 to $10 \%$. In these cases an increasingly higher maximum saturation is required so that the particles farthest from the centerline experience $S_{\text {liq }}=1$ (ice nucleation) and 1.07 (droplet breakthrough). The resulting activation curves of droplets and ice crystals are indistinguishable (i.e., a composite of the red and blue traces in panel a), historically the case for CFDC detectors (Rodgers, 1988), as shown in panel $b$. We propose that the shape of the idealized activation curve in Fig. 10b resembles that of experimental CFDC activation curves (DeMott et al., 2015) due to the primary importance of the particle spreading effect. 


\section{Conclusions}

The results presented here indicate that neither the reported thermodynamic conditions nor results from a single timing test capture the full variability of $f_{\text {lam }}$ in the SPIN CFDC. Following on the results of DeMott et al. (2015), the findings in this study indicate that $f_{\text {lam }}$ is not unity in real CFDCs. We show that it is also variable in ZINC and SPIN. We believe this is likely universal to all CFDC instruments although the degree of uncertainty and magnitude of the effect are probably a function of instrument geometry (parallel plate, cylindrical, etc.), flow and thermodynamic conditions. The nonuniform time which particles spend in a CFDC has complex results on ice nucleation and crystal growth, including larger and broader size distributions than predicted by theory.

A machine learning approach used housekeeping data to show that the most likely reason for the lack of ideality is small-scale flow features near the inlet of the chamber where the aerosol sample flow is sheathed. The RFR deemed variables including wall temperature, flows, and thermodynamic variables predominantly in the middle-to-top section of the SPIN chamber (i.e., at the injection point) as most important. Moreover, the RFR approach was able to better predict $f_{\text {lam }}$, and therefore the conditions experienced by the aerosols in the chamber than standard CFDC flow theory with an overall reduction in uncertainty by $\sim 60 \%$.

Finally, we show the particle spreading effect explains why CFDC chambers are often operated at non-physical $S_{\text {liq }}$ values to measure immersion-mode INP number concentration and why the reported numbers are strongly dependent on $S_{\text {liq. }}$. Theoretically, immersion-mode nucleation should occur at $S_{\text {liq }}=1$, yet reports with CFDCs often show increased concentrations up to, and often well beyond, 1.05. By contrast, CCN instruments routinely activate essentially all particles into droplets at 1.01-1.02.

We suggest laboratory work determining the extent of aerosol particle spreading variability be conducted for all CFDC chambers to minimize this bias and its variability. We suggest this work would (1) explore how experimental and chamber design influence the spreading effect, drawing comparisons to computational fluid dynamics simulations to complement the RFR statistical modeling and (2) which operational considerations (flow rates, inlet pressure drop, etc.) maximize the probability of isokinetic injection of particles into the chamber and (3) consider other freezing regimes such as depositional nucleation of ice.

Data availability. The data to this paper can be found at https://doi.org/10.7910/DVN/61UMMZ (Garimella et al., 2017).

Competing interests. The authors declare that they have no conflict of interest.
Acknowledgements. The authors gratefully acknowledge funding from NASA grant no. NNX13AO15G, NSF grant no. AGS1461347, NSF grant no. AGS-1339264, and DOE grant no. DE-SC0014487. Zamin A. Kanji and Robert O. David would like to acknowledge funding from SNF grant no. 200021_156581. We would like to thank the Storm Peak Laboratory staff for the use of their facilities to perform the pressure-dependent timing experiments. We thank Paul DeMott, Jesse Kroll and the Fifth Ice Nucleation workshop participants for helpful discussions.

Edited by: Hinrich Grothe

Reviewed by: two anonymous referees

\section{References}

Boose, Y., Sierau, B., García, M. I., Rodríguez, S., Alastuey, A., Linke, C., Schnaiter, M., Kupiszewski, P., Kanji, Z. A., and Lohmann, U.: Ice nucleating particles in the Saharan Air Layer, Atmos. Chem. Phys., 16, 9067-9087, https://doi.org/10.5194/acp-16-9067-2016, 2016.

Boucher, O., Randall, D., Artaxo, P., Bretherton, C., Feingold, G., Forster, P., Kerminen, V.-M., Kondo, Y., Liao, H., Lohmann, U., Rasch, P., Satheesh, S., Sherwood, S., Stevens, B., and Zhang, X.: Clouds and aerosols, in: Climate Change 2013: The Physical Science Basis, Working Group I Contribution to the Fifth Assessment Report of the Intergovernmental Panel on Climate Change, Cambridge, UK and New York, NY, USA, 571-657, 2013.

Breiman, L.: Random Forests, Mach. Learn. 45, 5-32, https://doi.org/10.1023/A:1010933404324, 2001.

Chou, C., Stetzer, O., Weingartner, E., Jurányi, Z., Kanji, Z. A., and Lohmann, U.: Ice nuclei properties within a Saharan dust event at the Jungfraujoch in the Swiss Alps, Atmos. Chem. Phys., 11, 4725-4738, https://doi.org/10.5194/acp-11-4725-2011, 2011.

DeMott, P. J., Cziczo, D. J., Prenni, A. J., Murphy, D. M., Kreidenweis, S. M., Thomson, D. S., Borys, R., and Rogers, D. C.: Measurements of the concentration and composition of nuclei for cirrus formation, P. Natl. Acad. Sci. USA, 100, 14655-14660, https://doi.org/10.1073/pnas.2532677100, 2003a.

DeMott, P. J., Sassen, K., Poellot, M. R., Baumgardner, D., Rogers, D. C., Brooks, S. D., Prenni, A. J., and Kreidenweis, S. M.: African dust aerosols as atmospheric ice nuclei, Geophys. Res. Lett., 30, ASC1-1-ASC1-4, https://doi.org/10.1029/2003gl017410, 2003b.

DeMott, P. J., Prenni, A. J., Liu, X., Petters, M. D., Twohy, C. H., Richardson, M. S., Eidhammer, T., Kreidenweis, S. M., and Rogers, D. C.: Predicting global atmospheric ice nuclei distributions and their impacts on climate, P. Natl. Acad. Sci. USA, 107, 11217-11222, 2010.

DeMott, P. J., Prenni, A. J., McMeeking, G. R., Sullivan, R. C., Petters, M. D., Tobo, Y., Niemand, M., Möhler, O., Snider, J. R., Wang, Z., and Kreidenweis, S. M.: Integrating laboratory and field data to quantify the immersion freezing ice nucleation activity of mineral dust particles, Atmos. Chem. Phys., 15, 393-409, https://doi.org/10.5194/acp-15-393-2015, 2015.

Forster, P., Ramaswamy, V., Artaxo, P., Berntsen, T., Betts, R., Fahey, D. W., Haywood, J., Lean, J., Lowe, D. C., Myhre, G., and Nganga, J.: Changes in atmospheric constituents and in radia- 
tive forcing, Chapter 2, Cambridge University Press, Cambridge, UK, 2007.

Garimella, S., Kristensen, T. B., Ignatius, K., Welti, A., Voigtländer, J., Kulkarni, G. R., Sagan, F., Kok, G. L., Dorsey, J., Nichman, L., Rothenberg, D. A., Rösch, M., Kirchgäßner, A. C. R., Ladkin, R., Wex, H., Wilson, T. W., Ladino, L. A., Abbatt, J. P. D., Stetzer, O., Lohmann, U., Stratmann, F., and Cziczo, D. J.: The SPectrometer for Ice Nuclei (SPIN): an instrument to investigate ice nucleation, Atmos. Meas. Tech., 9, 2781-2795, https://doi.org/10.5194/amt-9-2781-2016, 2016.

Garimella, S., Rothenberg, D. A., Wolf, M. J., David, R. O., Kanji, Z. A., Wang, C., Rösch, M., and Cziczo, D. J.: Uncertainty in counting ice nucleating particles with continuous flow diffusion chambers, Harvard Dataverse, V2, https://doi.org/10.7910/DVN/61UMMZ, 2017.

Järvinen, E., Schnaiter, M., Mioche, G., Jourdan, O., Shcherbakov, V. N., Costa, A., Afchine, A., Kraemer, M., Heidelberg, F., Jurkat, T., Voigt, C., Schlager, H., Nichman, L., Gallagher, M., Hirst, E., Schmitt, C., Bansemer, A., Heymsfield, A., Lawson, P., Tricoli, U., Pfeilsticker, K., Vochezer, P., Maehler, O., and Leisner, T.: Quasi-Spherical Ice in Convective Clouds, J. Atmos. Sci., 73, 3885-3910, https://doi.org/10.1175/JAS-D-15-0365.1, 2016.

Koop, T., Luo, B., Tsias, A., and Peter, T.: Water activity as the determinant for homogeneous ice nucleation in aqueous solutions, Nature, 406, 611-614, https://doi.org/10.1038/35020537, 2000.

Pruppacher, H. R. and Klett, J. D.: Microphysics of Clouds and Precipitation, Atmospheric and oceanographic sciences library, Kluwer Academic Publishers, Dordrecht, the Netherlands, 2nd Edn., 1997.

Rogers, D. C.: Development of a continuous flow thermal gradient diffusion chamber for ice nucleation studies, Atmos. Res., 22, 149-181, 1988.

Rogers, R. R. and Yau, M. K.: A Short Course in Cloud Physics, Third ed., International Series in Natural Philosophy, Pergamon Press, Oxford, UK, 1989.
Rossow, W. B. and Schiffer, R. A.: Advances in understanding clouds from ISCCP, B. Am. Meteorol. Soc., 80, 2261-2287, 1999.

Seinfeld, J. H. and Pandis, S. N.: Atmospheric chemistry and physics: From air pollution to climate change, WileyInterscience Publication, New York, USA, 2nd Edn., 2006.

Skrotzki, J., Connolly, P., Schnaiter, M., Saathoff, H., Möhler, O., Wagner, R., Niemand, M., Ebert, V., and Leisner, T.: The accommodation coefficient of water molecules on ice - cirrus cloud studies at the AIDA simulation chamber, Atmos. Chem. Phys., 13, 4451-4466, https://doi.org/10.5194/acp-134451-2013, 2013.

Stetzer, O., Baschek, B., Lüönd, F., and Lohmann, U.: The Zurich Ice Nucleation Chamber (ZINC) - A new instrument to investigate atmospheric ice formation, Aerosol Sci. Tech., 42, 64-74, https://doi.org/10.1080/02786820701787944, 2008.

Tobo, Y., Prenni, A. J., DeMott, P. J., Huffman, J. A., McCluskey, C. S., Tian, G., Pöhlker, C., Pöschl, U., and Kreidenweis, S. M.: Biological aerosol particles as a key determinant of ice nuclei populations in a forest ecosystem, J. Geophys. Res.-Atmos., 118, 10100-10110, https://doi.org/10.1002/jgrd.50801, 2013.

Vergara-Temprado, J., Murray, B. J., Wilson, T. W., O’Sullivan, D., Browse, J., Pringle, K. J., Ardon-Dryer, K., Bertram, A. K., Burrows, S. M., Ceburnis, D., DeMott, P. J., Mason, R. H., O'Dowd, C. D., Rinaldi, M., and Carslaw, K. S.: Contribution of feldspar and marine organic aerosols to global ice nucleating particle concentrations, Atmos. Chem. Phys., 17, 3637-3658, https://doi.org/10.5194/acp-17-3637-2017, 2017. 